\title{
Assessment of ear length and low set ears in newborn infants
}

\author{
YAKOV SIVAN, PAUL MERLOB, AND SALOMON H REISNER \\ From the Neonatal Department, Beilinson Medical Center, Petah Tiqva, Sackler School of Medicine, \\ Tel Aviv University, Israel.
}

SUMMARY In order to define normal values for ear length and position in the newborn infant, 198 (87 term and 111 preterm) infants were examined. In every case gestational age was determined chronologically and clinically. Ear length was measured from the superior to the inferior aspects of the ear. Using a horizontal line passing through the inner canthi of the eyes the portion of the ear above this line was measured, determining the position of the ear by its relation to total ear length. Normal values are presented by plotting the mean \pm 2 SD versus the gestational age. Small ears and low set ears are defined as values less than the mean -2 SD.

Ear defects are important in syndrome diagnosis in the newborn infant. Low set ears accompany many birth defects. ${ }^{2}$ Small ears have been found to be the most consistent clinical characteristic, apart from hypotonia, in making the diagnosis of Down's syndrome ${ }^{3}$ and are the most clinically apparent malformation in mandibulofacial dysostosis and hemifacial microsomia. ${ }^{4}$

However, normal values for ear length and position for term and preterm newborn infants are not available, particularly in relation to gestational age.

Because of the potential diagnostic implications of these signs the present study was undertaken in order to establish normal standards for these parameters from 27 to 41 weeks' gestation.

This paper is part of a detailed study attempting to establish normal standards for various parameters by gestational age and thus allowing the diagnosis of various syndromes even in the small preterm infant. ${ }^{5}$

\section{Materials and methods}

The ear length and position of 87 term (48 male and 39 female) and 111 preterm (55 male and 56 female) infants between the gestational ages of 27 and 41 weeks were measured. No congenital anomalies were observed in any of these infants. The gestational age was calculated from the first day of the last menstrual period. In every case clinical assessment of

Received for publication 14 September 1982. Accepted for publication 16 December 1982. gestational age was performed by the Dubowitz scoring system and by examination of the anterior vascular capsule of the lens ${ }^{6}$ (27 to 41 gestational weeks). Whenever a difference of 2 weeks or more was found the infant was not included in the study.

Measurements were made by two physicians with the technique described by Feingold and Bossert $^{7}$ using an instrument made from an $x$-ray film. Both sides of the instrument are divided into millimetres allowing the right and left ears to be measured by the same instrument. A central horizontal line is drawn on the instrument and the medial canthi are used as landmarks. The central horizontal line is placed over the inner canthi as the measuring part of the instrument covers the ear. The length of the ear above or below the centre line is determined and the total length of the ear is ascertained by measuring the distance between the most inferior and superior portions of the ear. The percentage of the ear above the line is determined by multiplying the measurements of the ear above the line by 100 and then dividing this number by the total length of the ear.

All measurements were made between 36 and 60 hours of age. The data presented are based on measurement of the right ear alone as it was not significantly different from the left ear.

\section{Results}

No statistical difference was found between boys and girls, and therefore the combined mean \pm 2 SD was used. The distribution of values approximates a 


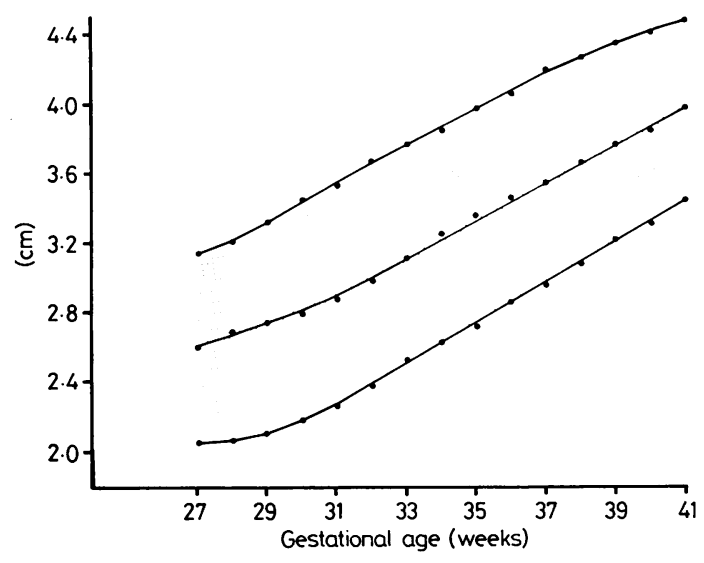

FIG 1 Total ear length. The points represent the mean value and $2 S D$ from the mean for each age group.

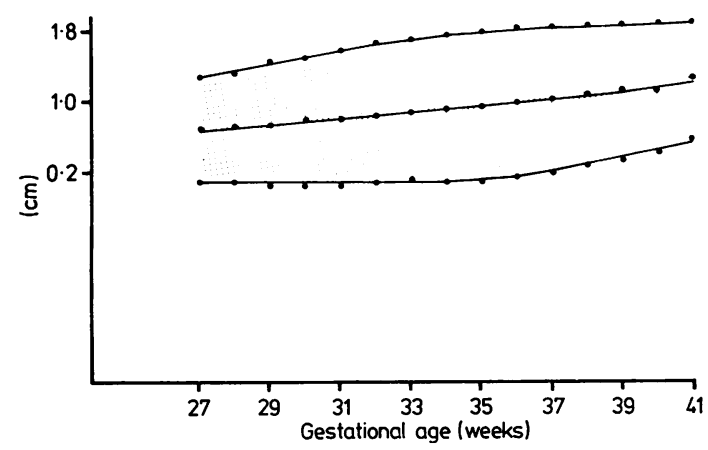

FIG 2 Ear length above eyeline. The points represent the mean value and $2 S D$ from the mean for each age group.

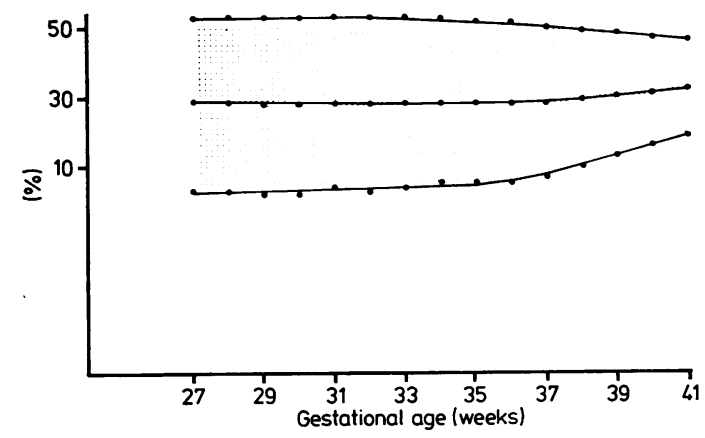

FIG 3 Percentage of ear above eyeline. The points represent the mean value and $2 S D$ from the mean for each age group.
Gaussian curve. Normal values (mean \pm 2 SD) for total ear length, ear above eyeline (centre line), and percentage of ear above eyeline are depicted in figs 1 to 3 . Fig 3 shows that the portion of the ear above the eyeline is quite constant during intrauterine growth.

\section{Discussion}

The purpose of this study was to assist the clinician in determining whether his newborn patient has low set or small ears.

On examination of the newborn infant, clinical impressions may be misleading because of the optical illusion of the infant having a high cranial vault, short mandibular ramus, short neck, or posterior rotation of the auricle around its axis. In the infant, the neck and ramus of the mandible are relatively shorter than the height of the cranial vault. ${ }^{89}$ Moreover, if the neck is extended, the ears appear low; if it is flexed, they appear high. Thus the ear length and position should be validated by quantitative criteria.

The present data allow the clinician to determine the presence of low set ears or small ears even in the very preterm infant.

As the length of the two portions of the ear (above and below the eyeline) increases during intrauterine growth the determination of the percentage of the upper part is essential in the diagnosis of low set ears.

Our results for term infants ( 37 to 41 gestational weeks) are similar to those of Feingold and Bossert. ${ }^{7}$ These measurements also provide information regarding the growth rate of the ear during intrauterine development.

The authors express their grateful acknowledgement to Dr Camiel Fuchs and Pearl Lilos of the Statistical Consulting Unit, Tel Aviv University, for their statistical analysis.

\section{References}

1 Smith DW. Recognizable patterns of human malformation. 2nd ed. Philadelphia: Saunders, 1976.

2 Bergsma D. Birth defects compendium. New York: The National Foundation-March of Dimes, Alan R Liss, 1979.

3 Aase JM, Wilson AC, Smith DW. Small ears in Down's syndrome. J Pediatr 1973; 82:845-7.

4 Hutchinson JC Jr, Caldarelli DD, Gould HJ. Classification and multi-disciplinary management of microtia. Otolaryngol Clin North Am 1981 ;14:855-87.

5 Sivan Y, Merlob P, Reisner SH. Philtrum length and intercommissural distance in newborn infants. $J$ Med Genet 1983;20:130-1. 
6 Hittner HM, Hirsch NJ, Rudolph AJ. Assessment of gestational age by examination of the anterior vascular capsule of the lens. J Pediatr 1977;91:455-8.

7 Feingold M, Bossert WH. Normal values for selected physical parameters: an aid to syndrome delineation. Birth Defects 1974;10:3-4.

8 Goodman RM, Gorlin RJ. Head and facial measurements. In: Goodman RM, Gorlin RJ, eds. Atlas of the face in genetic disorders. 2nd ed. St Louis: Mosby, 1977: 53-9.
${ }^{9}$ Gorlin RJ, Boggs WS. The genetic aspects of facial abnormalities. In: Harris $\mathrm{H}$, Hirschhorn K, eds. Advances in human genetics. New York: Plenum Press, 1970: 235-41.

Correspondence and requests for reprints to Dr Y Sivan, Neonatal Department, Beilinson Medical Center, 49100 Petah Tiqva, Israel. 